\title{
Supporting Creativity with Awareness in Distributed Collaboration
}

\author{
Umer Farooq, John M. Carroll, and Craig H. Ganoe \\ Computer-Supported Collaboration and Learning Laboratory, Center for Human-Computer Interaction \\ College of Information Sciences and Technology, The Pennsylvania State University \\ University Park, PA 16802 USA \\ \{ufarooq, jcarroll, cganoe\}@ist.psu.edu
}

\begin{abstract}
Based on qualitative analysis of three groups collaborating on a research task in a distributed setting, we identify four breakdowns in creativity: (1) Minority ideas were under-considered; (2) Novel ideas were easily lost; (3) There was a lack of critical evaluation of perspectives; (4) Reflexivity was weak during convergence. We propose two design strategies, illustrated with mock-ups, to support creativity with awareness: (1) Automatically summarize and recommend ideational activities from system logs; (2) Allow collaborators to enter status of work activity, making these activity updates visible on social and temporal dimensions. Our analysis also suggests an integrated framework of metrics to evaluate creativity as a long-term collaborative activity.
\end{abstract}

Categories and Subject Descriptors: H.5.3 [Group and Organization Interfaces]: Computer-supported cooperative work.

General Terms: Design

Keywords

Creativity support tools, awareness, collaboration, CSCW, HCI.

\section{INTRODUCTION}

Popular myth about creativity conjures lightning bolts of inspiration striking individual innovators without warning. A more typical, and perhaps even more important form of creativity than the isolated lightning bolt is relatively long-term and collaborative development of innovative ideas. Indeed, many industries and professions - research and development in information technology, for example - depend on this latter form of routine and deliberate creativity. Collaborating on writing a research paper is a typical example of routine creativity.

We do not yet have a clear understanding of what, where, and why breakdowns in creativity occur during long-term distributed collaboration, or of what could be done to avoid or mitigate these breakdowns with computer-supported cooperative work (CSCW) tools. To empirically investigate this challenge, we qualitatively analyzed traces of creative group behavior in a distributed setting. Identifying breakdowns led us to speculate how computersupported awareness can support creativity. Awareness is an understanding of the activities of others, which provides a context for one's own activity [8, 29].

Permission to make digital or hard copies of all or part of this work for personal or classroom use is granted without fee provided that copies are not made or distributed for profit or commercial advantage and that copies bear this notice and the full citation on the first page. To copy otherwise, or republish, to post on servers or to redistribute to lists, requires prior specific permission and/or a fee.

GROUP'07, November 4-7, 2007, Sanibel Island, Florida, USA.

Copyright 2007 ACM 978-1-59593-845-9/07/0011 ..\$5.00.
In this paper, we contribute in three ways. On an empirical level, we describe four breakdowns in creativity from a qualitative study: (1) Minority ideas were under-considered; (2) Novel ideas were easily lost; (3) There was a lack of critical evaluation of perspectives; (4) Reflexivity was weak during convergence. On a design level, we propose two strategies for awareness mechanisms to support creativity: (1) Automatically summarize and recommend ideational activities from system logs; (2) Allow collaborators to enter status of work activity, making these activity updates visible on social and temporal dimensions. We illustrate these design strategies with mock-ups. Finally, on a methodological level, our coding scheme suggests an integrated framework of metrics for evaluating creativity as a long-term collaborative activity. We discuss this toward the end of the paper.

\section{RELATED WORK}

Viewing creativity as a group phenomenon (see [27]), related work continues to explore the design, use, and evaluation of $\mathrm{CSCW}$ tools to support creative collaboration. For example, EVIDII allows designers to associate affective words and images and visualize them in context of what other designers have contributed [23]. Providing alternative representations evokes individual designer's creativity by using design knowledge or representations created by other designers in the community. Fischer [10] discusses several examples of collaborative environments to support creative processes. For example, in the Envisionment and Discovery Collaboratory [2], participants collaboratively solve design problems of mutual interest such as urban transportation planning. The assumption is that complex design is a social creative process, and the integration of individual and social creativity takes place through discussions in a shared space such as an electronic whiteboard. Interactive art [14] is based on the premise that computational media enable people to operate at the source of the creative process by creating a pool of pixema, individual pieces produced by different artists, which can be exchanged to synthesize new paintings.

Research has been sparse with respect to investigating the role of awareness in creativity support tools. In studying CodeBroker-a reuse support system that tracks the programming activities of software developers-Fischer [10] talks about how the system infers the developers' immediate programming task by analyzing semantic and syntactic information contained in their working products, and actively delivers task-relevant and personalized reusable components. Such awareness of others' work allows developers to focus on creative tasks not done before. Although awareness has been long acknowledged as a critical requirement for successful collaboration [8], it has not been studied from the perspective of exclusively supporting creativity in collaboration. 
We are investigating how creativity can be specifically supported through awareness in distributed collaboration. We are motivated by Burleson's [4] articulation to promote meta-cognitive strategies for creative pursuits. Our position is that awareness in distributed settings can support creative collaboration at a metacognitive level by allowing members to monitor and appropriately react to the group's creative process over time.

\section{STUDY CONTEXT}

Among many definitions of creativity, it is generally agreed upon that creativity is the ability to produce work that is innovative, implying both novelty and usefulness [20]. Novelty implies originality (e.g., a new idea) and usefulness implies relevance (e.g., application of the new idea and its relevance to the underlying task). The general definition of creativity also implies that it is both a process and product; that is, creativity involves a series of actions directed to some end.

We are specifically interested in scientific creativity. Csikszentmihalyi [7] defines scientific creativity as a process toward achieving an outcome recognized as innovative (both novel and useful) by the relevant community. The outcome of scientific creativity-essentially the goal of science-is the production of new knowledge. This new knowledge can be produced by individuals, groups, communities, or even societies. We are considering the co-construction of new knowledge by small groups, typically three to six members [3]. Co-construction of new knowledge is critical to our definition because it emphasizes coordination and resource sharing among group members (versus individual members independently doing their own tasks and only coming together to collate their contributions as a final product).

From the logical argumentation above, we define creativity as $a$ long-term, everyday scientific activity by members in small groups to co-construct new knowledge recognized as novel and useful by the relevant community. The long-term aspect of scientific creativity implies that the process is a significant endeavor directed at a major goal (such as collaborating on writing a conference paper). The everyday aspect of scientific creativity implies that the process is not an occasional occurrence (e.g., an "Aha" moment) but rather a routine practice of the members in small groups. In our definition, the novelty and usefulness of new knowledge is domain-dependent, relying on subjective assessment by one's relevant community.

The study context for our investigation is distributed settings (non-face-to-face) where group members collaborate synchronously and/or asynchronously through online workspaces (using collaborative tools such as chat, shared editors, and whiteboards). From our definition, creativity is scientific in nature, so the type of creative task we are considering is collaborating on writing a research paper. We chose this task because it typically represents creative scholarly activity.

\section{QUALITATIVE STUDY}

To empirically investigate how breakdowns in creativity in small groups can be supported through awareness, we followed a naturalistic research strategy using comparative case studies [3]. Three groups with three members each worked in a distributed setting on a collaborative task for one week.

\subsection{Participants}

Group members were recruited from the graduate student population at a large university majoring in computer and information science. We formed three groups opportunistically based on availability of participants to volunteer for the study.

\subsection{Task details}

Each group was asked to write an opinion piece (approximately 1000 words) related to computer science education, specifically on introducing and teaching software programming to new computer science students. This task was chosen as being appropriate for the subject population and because recently, in Communications of the ACM, opinion pieces have been published on this topic (e.g., [19]). The groups were instructed that they would be assessed on the creativity of their opinion piece. As guidance to the groups, they were given a foundation paper by Westfall [34], and were be asked to expand, critique, or base their opinion piece on this paper.

\subsection{Tools}

Group members worked on the shared task in a collaborative environment called BRIDGE (Basic Resources for Integrated Distributed Group Environments; http://bridgetools.source forge.net; see [13]). The BRIDGE Java-based client supports shared editing of documents through replicated objects. Replicated objects are objects that are retrieved by multiple collaborating sessions and whose state is kept synchronized on all clients and a server when any replica is changed. The following collaborative artifacts were provided in BRIDGE: persistent chat tool (to communicate), wiki-based brainstorming space (to develop ideas), and concept map (to visualize ideas). The groups produced their final report in a wiki-based document called "opinion piece". All these artifacts supported synchronous and asynchronous collaboration.

\subsection{Procedure}

For each group, all three members were invited to an initial kickoff face-to-face meeting (approximately 25 minutes). Each member was introduced to the others and given an informed consent form. The researcher explained the task, demonstrated the use of BRIDGE, and clarified any issues related to the task or technology. The researcher emphasized that the collaboration should be carried out only through BRIDGE and that the final opinion piece would be evaluated based on its creativity. Approximately five minutes toward the end of this meeting were allotted for social grounding [18]. Based on pilot testing, we considered it essential to provide group members with a face-toface opportunity to establish initial common ground and strategize about their collaboration for the subsequent duration of one week (D0 to D7, where 'D' stands for 'Day').

\subsection{Data collection}

During the kickoff meeting, we collected demographic data. Participant creativity scores were also obtained using a 30-item creativity scale derived from the adjective checklist (ACL) [15]. There are 18 positive items and 12 negative items on this scale. Each positive item adds one point to an individual's creativity score and each negative item results in a one-point deduction. Thus, the minimum and maximum creativity scores are -12 to +18 . Table 1 summarizes the participants' background data (all names have been anonymized).

During the experiment, all interactions in BRIDGE were logged on the server. For example, communication messages in the chat $\log$ and changes to shared data were recorded with time stamps. To periodically check on the group's progress, the investigator e- 
mailed each participant individually on days D2 and D4 asking for a brief update (approximately 2-3 sentences) on the task.

After the experiment, semi-structured interviews (approximately 30 minutes) with each participant were conducted. The questions asked participants about their reflections on the creative process (e.g., How were novel ideas generated and implemented?).

Table 1. Background data of participants.

\begin{tabular}{|c|c|c|c|}
\hline Name & Group & $\begin{array}{c}\text { Academic } \\
\text { background }\end{array}$ & $\begin{array}{c}\text { Creativity } \\
\text { score }\end{array}$ \\
\hline Ahmed & Bravo & CS/Psychology & 6 \\
\hline Chris & Bravo & CS & -4 \\
\hline Judy & Bravo & CS/Psychology & 2 \\
\hline Dipak & Echo & CS/Communications & 5 \\
\hline Sam & Echo & CS/Math & 13 \\
\hline Wendy & Echo & CS & -3 \\
\hline Hasan & Foxtrot & CS & 2 \\
\hline Jay & Foxtrot & Information Science & -1 \\
\hline Marie & Foxtrot & CS Engineering & 10 \\
\hline
\end{tabular}

\subsection{Data analysis}

Following a case study approach [37], we treated each group as a distinct case. We read, summarized, re-read, and compared each case with the others, thus providing a rich cross-case interpretation. We primarily followed a qualitative analysis approach to understand and identify breakdowns in creativity. We also report (but have not fully analyzed) some quantitative measures as secondary sources of data collection to understand the holistic process of creativity.

\subsubsection{Understanding group participation}

We extracted data related to group participation from the server logs. For example, we extracted the total number of sessions for the brainstorming space and final opinion piece (a session is one continuous interaction during which group members change the artifact). We counted the number of words typed in the chat tool. We also counted the number of synchronous chat sessions (when at least two group members are logged in at the same time and communicate interchangeably).

\subsubsection{Breakdown analysis and coding scheme}

The communication in the chat logs was analyzed for content. We coded the chat logs for breakdowns in creativity. A breakdown is a problem in system use that interrupts a person's activity, making him or her more conscious of the system, and less able to focus on the activity that the system is supporting [35]. In our study context, we consider a breakdown as a disruption in "flow" [7], a necessary characteristic of creativity.

We adapted Carroll's et al.'s [5] method for analyzing collaborative breakdowns for our context of using CSCW systems to support creative group activity. Collaborative breakdowns involve multiple inter-related problems experienced by different collaborators, and they typically require a combination of actions taken by multiple agents to diagnose and repair.

We used the theory-driven conceptual framework from our prior work [9] to deductively develop an integrated coding scheme for analyzing breakdowns in creativity from the chat logs. We coded occurrence rather than frequency because our goal was to identify a range of issues that led to breakdowns in creativity. This approach is appropriate for exploratory data where the focus is on hypothesis generation rather than hypothesis confirmation [5].
Our theoretical coding scheme consists of five macro-level codes, each comprising several micro-level codes. We briefly discuss our codes below to provide the reader with a basic understanding of our analysis. Coded examples from the data are provided at the end of the paper (see appendix).

(1) Social influence. We have identified five types of social influence that affect creativity in groups:

(a) Groupthink: Part of the reason for suboptimal performance in creative groups is that members desire consensus. This is known as groupthink, arising from a situation marked by homogeneity of its members, strong and directed leadership, group isolation, and high cohesion [17].

(b) Normalization: This is the process whereby the "reciprocal influence of group members induces them to formulate or to accept a compromise" [22, p. 208]. Normalization can occur within creative groups where the majority of members do not have a well-defined norm or solution, and they converge on an average response [26].

(c) Majority influence: This can occur in situations when a minority opinion holder(s) exist among a group of otherwise majority opinion holders [26]. The majority achieves influence as it exerts social pressure on the deviant minority opinion holder, causing him or her to conform to the majority opinion so that the group can achieve uniformity [26].

(d) Polarization: When group members favor a particular side of an issue but differ in their specific judgments, discussion often leads to consensus, but the consensus position is more extreme than the average of the individual judgments [24]. This is known as polarization, the notion that shared beliefs exacerbate perceptions and behaviors [24].

(e) Minority dissent: Dissenting opinions stimulate divergent and creative thought [24]. It is the situation when initially unpopular views still get considered and remembered, thus making the group's total inventory of ideas richer.

(2) Information sharing. A necessary condition for creativity is for group members to develop shared objectives, which requires them to leverage their domain-specific knowledge and engage in information sharing [25]. Broadly, a group can pool information in two ways [30]:

(a) Common information pooling: This is information known by all members prior to discussion.

(b) Unique information pooling: This is information held by one member before group discussion.

(3) Shared understanding. Shared understanding is the extent to which members collectively reflect on the group's objectives, strategies, and processes [31]. Also known as group reflexivity [32], shared understanding consists of three elements:

(a) Reflection: This consists of attention, awareness, monitoring, and evaluation of the object of reflection. It is about critical thinking, which is thinking that is focused, disciplined, logical, and constrained [25].

(b) Planning: This is one of the potential consequences of the indeterminacy of reflection because courses of action can be contemplated, intentions formed, plans developed, and the potential for carrying them out is built up [33].

(c) Action/adaptation: This refers to goal-directed behaviors relevant to achieving the desired changes in group objectives, 
strategies, processes, organizations, or environments identified by the group during the stage of reflection [33].

(4) Divergent thinking ${ }^{1}$. This is the process of taking different perspectives and generating alternative solutions. Divergent thinking can be manifested in three ways:

(a) Generation of multiple perspectives: This involves generating a set of novel ideas. A wider range of perspectives is more likely when several members approach an issue or problem from different angles or backgrounds [21].

(b) Reflection of multiple perspectives: Another way that divergent thinking promotes creative cognition is the degree to which a group considers multiple alternatives before committing to any one decision or course of action [16].

(c) Unique information pooling: Another manifestation of a group's capacity for divergent thinking is the degree to which members are willing to share unique information [21]. Note that this micro-level code also occurs under "information sharing", implying that unique information pooling can even happen beyond the group's stage of divergent thinking.

(5) Convergent thinking ${ }^{1}$. In addition to divergent thinking, convergent thinking allows groups to select from available options and put these ideas into practice. This involves two steps:

(a) Critical evaluation of perspectives: This involves funneling down a set of ideas or opportunities into a manageable decision from which to proceed to implementation [21].

(b) Perspective implementation: Selected ideas must be not only novel but practically feasible as well [21]. Perspective implementation involves the execution of a selected idea.

We identified breakdowns in creativity based on the data from our cases and literature review in [9]. Based on the analysis of the three cases and what the literature tells us in general about creative groups, we characterized positive episodes of group creativity that we then used as comparative benchmarks to identify breakdowns in our specific experimental context.

An independent researcher, not part of our team but who was familiar with creativity research, reviewed our coding scheme and discussed practical issues of applying the codes with the principal investigator (first author). With a small data sample, one of the issues discussed was the evidence in the chat communication that is required to categorize a data snippet with a particular code. For example, it was agreed that a unique idea (as a result of "unique information pooling") was one that had not been discussed before in the group.

In addition to our coding scheme, we also recorded collaborative dynamics in our experimental groups. For example, we observed that in Bravo, Ahmed's minority idea caused group conflict that eventually led him to be marginalized by the other two group members. We acknowledge that such collaborative dynamics are interweaved with creativity. For the scope and length of this paper, we focus less on illustrating these collaborative dynamics in our data and give precedence to the dynamics of creativity and its associated breakdowns.

\footnotetext{
1 Note that we are defining the "processes" of divergent and convergent thinking, not characteristics of a "task". A divergent task is one with multiple correct answers and a convergent task is one with a single correct answer.
}

\subsubsection{Assessing creativity of product}

Based on Amabile's [1] consensual technique for creativity assessment, the level of creativity in each group's final opinion piece was assessed independently by two judges. We took the average of the judges' ratings on a creativity scale from 1 (low) to 10 (high) (see details of assessing creativity of product in [26]).

\subsubsection{Data triangulation}

We also culled and collated user quotes from the two progress reports and interviews by identifying appropriate instances that helped to triangulate our collaborative interpretation of the data. The use of other collaborative artifacts (e.g., brainstorming space) also facilitated this process.

A research challenge we encountered was the accurate identification of breakdowns because of their subjective nature. For example, participants may not consider what an investigator perceives as groupthink. The progress reports helped the researchers perform member checking by corroborating their analytical perspective on the data.

\section{BREAKDOWNS IN CREATIVITY}

We now turn to the results of our qualitative analysis. Although we observed many breakdowns during the creative group activity, we only report four of these for the purposes of this paper. Our goal is to identify those breakdowns that can be potentially supported with awareness mechanisms.

Table 2 summarizes group level descriptives. Members in Bravo communicated and collaborated the least in comparison to the other two groups. Only two members (Ahmed and Chris) changed the brainstorming space thrice among themselves; Judy did not contribute to this space. Chris and Judy individually wrote their final opinion pieces (that were integrated by the investigator into one piece for assessment); Ahmed did not contribute content to Chris or Judy's opinion piece.

Table 2. Group level descriptives.

\begin{tabular}{|l|c|c|c|}
\hline & Bravo & Echo & Foxtrot \\
\hline Brainstorming space & & & \\
\hline \# of words & 338 & 929 & 1797 \\
\hline \# of sessions & 3 & 10 & 14 \\
\hline Final opinion piece & & & \\
\hline \# of words & 537 & 1780 & 716 \\
\hline \# of sessions & 0 & 20 & 3 \\
\hline Chat communication & & & \\
\hline \# of typed chat words & 1443 & 3689 & 1712 \\
\hline \# of synchronous sessions & 2 & 4 & 2 \\
\hline Group creativity score & 4 & 15 & 11 \\
\hline Creativity of opinion piece & 3.8 & 5 & 4.5 \\
\hline
\end{tabular}

Members in Echo communicated the most. They collaborated moderately using their brainstorming space but collaborated the most on their final opinion piece by iterating 20 times. Echo members decided to finish their opinion piece a couple of days before the due deadline. All members contributed to the brainstorming space and opinion piece.

Members in Foxtrot communicated moderately. Foxtrot members indicated in their interviews that they also used the brainstorming space for communication, which explains the high frequency of words and sessions in the brainstorming space. Hasan and Jay were relatively more active than Marie. Marie was not part of any 
session changes to the final opinion piece and only contributed to one session change in the brainstorming space.

Table 2 also shows the group creativity score (sum of individual creativity scores). Groups with higher group creativity scores scored higher on the creativity of their opinion piece. Following are the breakdowns that we identified from our analysis.

\subsection{Minority ideas under-considered}

During cognitive conflict and dissent, one of the breakdowns in creativity that we observed was the under-consideration of minority ideas. This was mainly due to normalization or majority influence in the group, resulting in the dismissal of dissenting ideas that may have been novel. The following snippets from Bravo and Echo's group dynamics illustrate this point.

Bravo: Ahmed's “debate” idea dismissed readily. Ahmed joined the group discussion late on day D2, apologized for being absent, and indicated that he is "caught up on the reading". Ahmed proceeded immediately to share his view of the task and proposed a "point-counterpoint type debate" among the Bravo members. Judy replied the same day and was hesitant to further explore Ahmed's idea; she said: "I don't think we have time or space for a debate". At the same time though, she did ask Ahmed for "educational-like examples" to elaborate on his debate topic, which Ahmed did not provide.

In the second set of progress reports, Chris said he was open to Ahmed's idea of a debate; but Judy dismissed Ahmed's approach, attributing this decision as a collective process ("we have kind of decided..."). After a hiatus, Ahmed only reappeared in the group discussion on D7. Communication on this day was chaotic. Ahmed and Judy exchanged multiple threads of synchronous communication, with Ahmed pushing for his debate idea and Judy chiding at his approach, providing explanation of why the debate topic is not worthwhile. Judy abruptly ended her communication by concluding, "it is too late". In his interview, Ahmed was candid about his feelings toward Judy, expressing his discontent by asserting that "she $\{$ Judy said it was too late repeatedly and it wasn't too late".

Echo: Misunderstanding about Sam's "syllabus" idea. On D2, Sam and Wendy chatted synchronously about materializing their top-down approach to programming. Sam proposed to include an "outline of the course" that would summarize the topics to teach as part of the top-down approach. Wendy asked, "Do we need to?", trying to understand whether "advocating a course" was part of the task scope. Sam said that without a concrete example, such as a course outline, the opinion piece would not be able to "show what we mean by top-down approach". Wendy agreed. Dipak missed this chat session on D2.

When Echo reconvened for another synchronous chat session on D3, they started to divide the sections with Sam asserting, "I can do why this is a novel approach and the syllabus". Dipak, not knowing the context of the prior meeting, immediately replied in confusion: "Why are we making a syllabus, again?" Sam proceeded with his arguments once again, reiterating his rationale that he communicated to Wendy the previous day, after which Dipak implicitly agreed and asked if the syllabus would better fit in the "teaching methods" section rather than the "novel approach" section. Wendy immediately reacted: "it appears so". Thereafter, Dipak summarized the content of the proposed opinion piece without any reference to the "teaching methods" section. During task allocation, Sam opted for the "novel approach" section and asked Dipak whether he will do the "proposed teaching methods" section. Dipak complied. However, the syllabus was never written about in the final opinion piece.
In his interview, Sam, whose idea it was to include the syllabus, reflected deeply on what happened: "After one meeting...the syllabus part got into the outline. But then it got removed in the next outline. It was Wendy who said that to remove the outline\}". Sam displayed a strong feeling while reflecting on his contribution. When Wendy was probed about the syllabus idea during her interview, she hedged her feelings toward the syllabus and gave a defensive response: "We kind of like agreed with him $\{\mathrm{Sam}\}$ in the end. It $\{$ the syllabus $\}$ did become part of the final piece." In actuality, it never did.

Implications. From our analysis, there is clearly a need to preserve minority ideas and make it easier to retrieve, reconsider, and reflect on them. Documenting cognitive conflict and dissent, the rationale for such minority ideas, and how group members influenced and decided their outcome can allow collaborators to reappraise the situation and enhance their confidence in the group's creative solution.

\subsection{Novel ideas easily lost}

The novel ideas generated and narrowed down by group members in prior interactions did not fully carry over to subsequent interactions, were not readily available for review, and/or could not be easily integrated. As a result, novel ideas were easily lost, either for part of the group interaction such as in Bravo, or for the entire duration of the task as it happened in Foxtrot.

Bravo: Ahmed did not know about the "animation" idea. On D0 and D1, Chris and Judy brainstormed the possibility of doing "something with the animation idea" as an approach to teaching software programming. Because Ahmed joined late, he did not know about this "animation" idea. Ahmed claimed to have caught up on the reading but did not read or reflect on the previous chat communication between Chris and Judy. As a result, Ahmed did not fully reflect on the animation idea that Chris and Judy agreed upon as a topic for the final opinion piece. The first set of progress reports corroborated this lack of shared understanding among the group members. Ahmed seems disappointed, as he does not have a "real sense" of what his collaborators were doing.

Foxtrot: Hasan's "sequencing concepts" idea did not carry over. On D1, Foxtrot members communicated effectively with each other by sharing different perspectives and narrowing their approach to "teach students with no programming experience". On D4, for which all the group members had planned to meet synchronously at a common time, only Hasan and Jay came online. Hasan decided that he and Jay should proceed as Marie "can read this chat window next time she $\log \{s\}$ on". Both of them contributed ideas and integrated them to narrow their teaching approach toward separating "OO programming philosophy from coding". When Hasan suggested deciding on "concepts" that would be "introduced to new students and in what sequence", Jay had to leave and said: "How about we just stop here today". Jay then volunteered to write a "summary" in the brainstorming space "so that Marie can read it later."

Jay's summary of his discussion with Hasan in the brainstorming space (D4) was quite detailed. However, the summary did not include Hasan's last idea in D4's chat session regarding the sequence of concepts to be taught to students. As a result, Hasan's idea was never incorporated into the final opinion piece.

Implications. Our analysis suggests that a recap of interaction history, specifically for novel ideas, is important for group members to have access to. Prompting group members to create interim summaries or automatically summarizing interaction history across time can provide context for future interactions and 
facilitate a meaningful codification of the novel ideas during divergent and convergent thinking.

\subsection{Lack of critical evaluation of perspectives}

Another breakdown we observed was the hasty decision by groups in choosing which ideas to converge on and implement. This resulted in a lack of critical evaluation of perspectives. In the case of Bravo, this was due to time limitations, whereas in the case of Echo, it seemed like the members experienced groupthink.

Bravo: Time-pressured consensus. Since their first interaction on D0, Chris and Judy agreed on the "animation" idea. Instead of developing or reflecting on this idea further, the group was mired in conflict over Ahmed's debate idea. Bravo found themselves racing against time. On D6, Judy reflected on the looming deadline ("We need to get on this today") and shared a few concrete ideas to implement. On D7, Chris was still confused about the overall task requirements and asked whether it would be appropriate to just submit "an idea report".

Echo: Quickly decided on "top-down" approach. On D0 and D1, Echo members communicated synchronously in an organized manner. Each member contributed to the discussion, generated ideas, and converged early on "a top-down approach, introducing students to programming via projects that are 'fun' and likely more engaging" (brainstorming space). The first set of progress reports indicated that all the group members were on the same page. Part of the reason for quickly deciding on an approach without critical evaluation was Echo's highly cohesive and complacent approach to the creative group task.

During the whole collaborative process, group members efficiently allocated tasks. Wendy asked if they should "divide sections" to which Sam replied, "we can make an outline... and then everyone can contribute to any section". The chat communication was supplemented by work summaries written in the brainstorming space. For example, on D3 and D4, Dipak posted the following respectively in the brainstorming space: "We have decided to split the writing of the final piece... \{ outline of final piece\}" and "We briefly met to agree... \{summary of chat discussion\}". Even during synchronous chat sessions, Echo members summarized their work periodically. For example, on D2, Wendy said in the beginning of Echo's synchronous chat session: "ok so lets summarize wat $\{$ what $\}$ we have".

Implications. In addition to summarizing interaction history, group members need a workspace for reflection where they can discuss pros and cons of novel ideas, provide an exegesis, and decide how a particular idea would be implemented.

\subsection{Weak reflexivity during convergence}

Part of producing a creative output is to have a shared understanding to allow for focused implementation of novel ideas. We noted that Bravo and Foxtrot exercised weak reflexivity during convergent thinking during which the groups dissipated in their collective effort to develop a coherent opinion piece.

Bravo: No one knew the status of the opinion piece. Individual interviews indicated that none of the group members knew exactly what happened to the final opinion piece. Judy said she "was hoping" that Chris would add to her contribution and then asked the investigator if $\mathrm{s} / \mathrm{he}$ knew the outcome. Chris implied that there were "no big differences" between what he and Judy wrote, and said that he did not know what Ahmed produced. Showing dismay over the collaborative process, Ahmed said his group members "were just sort of doing their own things".

Foxtrot: Every man for himself. After D5, the discussion between Foxtrot members petered out and only Jay contributed to the brainstorming space thereafter. On D6, Jay requested his group members to converge on their ideas in order to meet the deadline on D7: "And since tomorrow morning we will deliver our final product, I suggest all of us make our ideas clear and see how we can put them together." Receiving no reply, either in the chat tool or brainstorming space, he integrated prior ideas and informed his group members: "...here is... what I get based on what we discussed so far. If you have other ideas, just put in it, or revise it directly." On D7, yet again without any reply, Jay wrote his last message in the brainstorming space: "...I put... what I have in the 'Final opinion piece'... Feel free to modify or add new stuff in it." Only Hasan added content on D7 to the final opinion piece but did not alter Jay's contribution.

Jay's reaction in the interview reflected on the "weak" collaborative process, especially "towards the end". Hasan thought that their opinion piece was not as creative as it could have been. He expressed a desire to see a "summary" and "history" of previous interactions so that ideas are not lost. He said: "I would like to see what happened yesterday related to something the day before". Marie reiterated Hasan's thoughts, strongly expressing a need for tools to create a "chain" between the ideas being shared, which otherwise seem like unconnected "blurbs" that people leave "up there".

Implications. This breakdown was a result of more than just a lack of explicit task allocation. Group members need an integrated view that networks and combines their contributions in a meaningful way and provides a social and temporal index of who is doing what and when.

\section{DESIGNING FOR AWARENESS}

The breakdowns in creativity that we identified, in general, highlight the need for groups to have their own work re-presented to them. Our analysis of the data suggested to us that the breakdowns stem from a failure of activity awareness [5, 6].

Activity awareness is awareness of collaborators' work that supports performance in complex tasks in long-term endeavors directed at significant goals. Activity awareness implies cognizance of other people's plans and understandings, knowledge of what one's collaborators are doing, and identifying, coordinating, and carrying out different types of task components, such as assigning roles, making decisions, negotiating, and prioritizing This dynamic and longitudinal aspect of activity in activity awareness, which has its roots in Activity Theory, aligns with our long-term view of everyday scientific creativity.

Below, we describe two design strategies for activity awareness mechanisms to support creativity in distributed collaboration. We illustrate these strategies with design mock-ups.

\subsection{Log-based ideational summaries}

Log-based ideational summaries can address the first three breakdowns from our results. The gist of this design strategy is to automatically summarize and recommend ideational activities from system logs.

Consider a creativity support tool that allows group members to enumerate ideas they are generating during divergent thinking, list pros and cons of each idea, and rank each idea along the creative process as more ideas come into play and/or pros and cons are added. Given that such an "idea workspace" is provided to groups and all actions in such a workspace are logged by the collaborative system, it is possible to summarize the activities of users by mining the logs, coalescing user actions to generate a meaningful précis of changes in the idea workspace, and recommending further actions to the collaborators. 
Consider the following use scenario of an idea workspace in BRIDGE. In Figure 1, Ahmed from group Bravo adds his "pointcounterpoint debate" idea to the workspace. He annotates an advantage to his idea by commenting that it is "very creative" and ranks it by either choosing "agree" or "disagree". At a later point, Judy logs into the system, comments on two disadvantages of implementing Ahmed's idea, and disagrees with the approach. Chris also disagrees with the debate idea. All these changes to the idea workspace are assumed to be logged by BRIDGE.

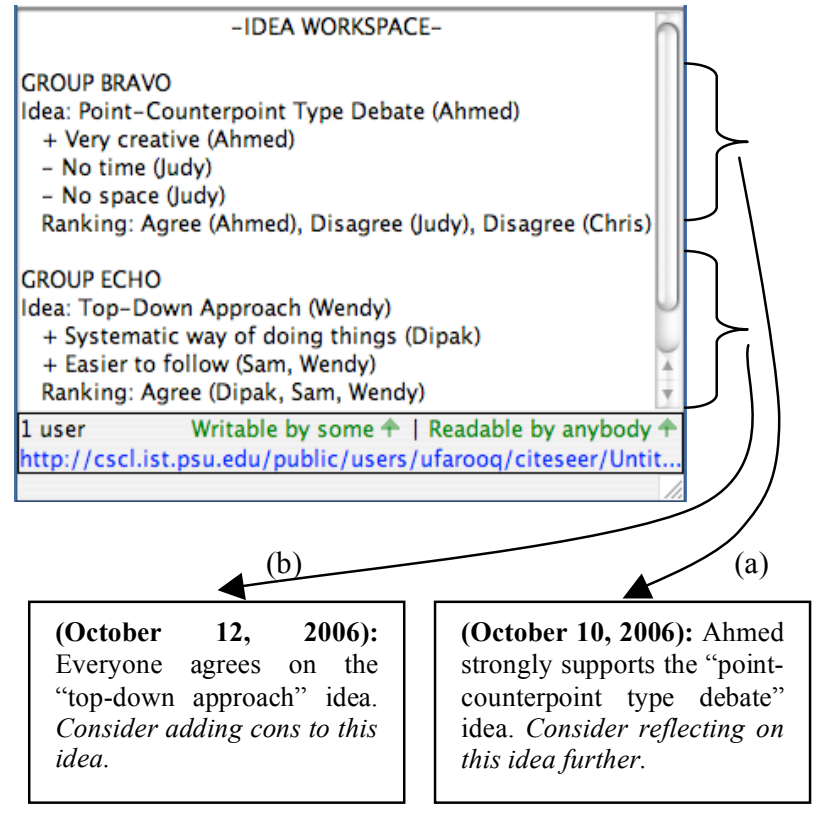

Figure 1. Automated log-based summaries based on user activities in an idea workspace. (a) Summary provides activity awareness of minority dissent to Bravo members. (b) Echo members are apprised of possible groupthink.

Based on this information in the system logs, BRIDGE can make an inference that Ahmed's idea is a minority opinion, established by the conditions that he suggested the idea, commented only on the idea's advantage, and agreed, whereas the other group members commented on the idea's disadvantages and disagreed with the idea. A system recommendation, as shown in Figure 1(a), makes the group aware of their activities by summarizing the changes in the idea workspace and prompts them to consider further reflection.

Consider another example from our data illustrated in Figure 1(b). In the group Echo, all members quickly decided on the idea of a "top-down approach". As everyone agreed to the idea and commented only on the advantages of such an approach, the system could make an inference from the log that the group should consider adding negative consequences to the idea. In a way, the system is making the group aware that their activities related to this idea may be a consequence of groupthink and is prompting them to ultimately reconsider their ranking.

An activity awareness mechanism such as providing log-based ideational summaries could be extended to other breakdowns in creativity. For example, our second breakdown suggested that novel ideas got lost. In the idea workspace, if an idea has not been commented upon and no one has ranked it based on some specified time threshold, the system can make the group aware that the idea has been dormant for some time and may require the members to comment on it. In this way, the group is made cognizant of a possibly good idea that may otherwise get ignored.
In general, recommendations to collaborators can serve as reminders to critically evaluate different perspectives in the idea workspace.

We think that providing log-based ideational summaries is a feasible activity awareness mechanism to support creativity. Foremost, the activity awareness information is automatically being generated from system logs without the intervention of users. This is an attractive characteristic that is practically possible, as recently, other systems have implemented such task support based on system logs [28].

Automatically generating log-based ideational summaries has design challenges. First, the design depends on having some sort of idea workspace where users go through the process of ideation in a structured manner. In our mock-up, the design innovation is not the "idea workspace" but rather the "log-based ideational summary", as the former is only proof-of-concept for a tool that supports creative activities. The notion of a structured idea workspace itself is not far-fetched. Ideational tools, where collaborators follow protocol and interact in a structured way so that systems are able to log user activities, have been talked about in CSCW since early days. A classic example of such a system is Cognoter [12].

Another design challenge is the degree to which the collaborative system can make relevant and useful inferences. In our scenarios, BRIDGE was simply aggregating the user activities and recommending further actions based on pre-defined rules (e.g., if all members agree to an idea, they are experiencing groupthink, so suggest further reflection). One could certainly imagine a recommender system that mines user activities for patterns, uses machine learning techniques to learn from a training set, and then suggest or predict intelligent actions based on past user behavior. We will explore this approach as future work.

On a user interface level, we have shown the log-based ideational summaries as text-based prompts to users. Our immediate work is focusing on presenting ideational summaries visually when users $\log$ into the collaborative system. For example, one implementation we are considering is to show ideational summaries on a timeline so that group members can get an overview of what they are doing and what needs to be done across time.

\subsection{Structured activity updates}

Structured activity updates can address the fourth breakdown of weak reflexivity during convergence. The design strategy is to allow collaborators to enter status of their work activity, making these activity updates visible on social and temporal dimensions. During convergence, collaborators can be prompted to enter what they are currently doing. These updates can be structured based on the type of activity they are engaged in. In Figure 2, we illustrate three examples. An action update (indicated by maroon arrow) allows collaborators to specify their current task. A query update (question mark) lets collaborators ask their group members a question related to their current task. A comment update (cloud callout) is a general remark on one's current task.

The activity updates are structured in the sense that each collaborator is presented with a template to update his/her status. For each of the three types of updates, a collaborator (take Sam as an example from the group Echo) could be presented with a template that resembles the following:

- Action: Sam is working on

- Query: Sam is asking to

- Comment: Sam is thinking that his task is 
When Sam updates his activity status, he can choose one of the update types and enter text in the blank space or even choose from a drop-down list of possible updates. Figure 2 shows these structured activity updates that users can enter during their collaborative sessions. Clicking on an icon for the update type (e.g., black mouse pointer clicking the maroon action update arrow) highlights the update in the "activity updates" console below the timeline.

\begin{tabular}{|c|c|c|c|}
\hline $\begin{array}{r}\text { Sam } \\
\text { Wendy } \\
\text { Dipak }\end{array}$ & Oct 17 & Oct 24 & \\
\hline \multicolumn{3}{|c|}{-ACTIVITY UPDATES- } & \\
\hline \multicolumn{4}{|c|}{$\begin{array}{l}\text { Sam is working on "adding his syllabus idea to the } \\
\text { final opinion piece". }\end{array}$} \\
\hline \multirow{2}{*}{\multicolumn{3}{|c|}{$\begin{array}{l}\sim \text { Wendy is asking "Sam" to "think about whether or } \\
\text { not the syllabus idea is a good one". } \\
\sim \text { Dipak is thinking that his task is "easy and is } \\
\text { willing to help others on their work". }\end{array}$}} & \\
\hline & & & 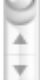 \\
\hline
\end{tabular}

Figure 2. Structured activity updates for group Echo. Icons highlight the updates on social (who entered the update) and temporal (when was the update entered) dimensions.

Showing activity updates on social and temporal dimensions can allow group members to easily identify who has updated their activity status and when. Such awareness information about collaborators' activities can facilitate reflexivity during convergence as group members can reinforce their shared understanding about who is doing what, how they need to recalibrate their tasks with respect to others, how everyone's tasks will come together as one final product, and so forth.

Our design strategy of structured activity updates was inspired by status prompts on social networking websites such as Facebook (http://www.facebook.com) and Twitter (http://twitter.com). These sites allow users to enter any general comment about themselves (e.g., "I am glad the semester is over"; "I am craving pizza") that is then broadcasted to others in their social networks. Whereas these social networking sites allow users to enter any informational updates, our proposed updates are activity-centric, that is, they are related to the collaborators' task at hand. By structuring the updates in pre-defined activity-centric templates, we believe users will be prompted to think in terms of what they are doing with respect to their task.

One of the design challenges to consider is how much structure in the activity updates is "too much" as one could argue that the open-ended nature of status updates on Facebook and Twitter has made the feature popular. Perhaps more importantly, status updates on these social networking sites have an implicit reward mechanism in that users are updating a huge critical mass of their friends in their network by entering a few words. In our task context, we are considering members in small groups on the order of three to six collaborators; it may not be worthwhile for a group member to enter an activity update for apprising such a small number of collaborators. Furthermore, activity updates should be integrated with the users' workflow and should not hinder the creative process. One way to address this challenge is for the design to be compelling enough so that users actually find entering their updates useful, not only in the service of others but also for themselves. In software teams, for example, CVS (Concurrent Versioning System) prompts programmers to enter comments when checking in their software code. A recent study has shown that such comments, when supplemented with lightweight communication, are useful for software coordination [11]. This study is encouraging for our design strategy, as structured activity updates could be considered as lightweight communication mechanisms for collaborators. For example, in Figure 2, Wendy's reflection on Sam's activity update could be considered lightweight communication between Wendy and Sam.

Our immediate work is considering how structured activity updates can be better represented as user interface widgets on social and temporal dimensions. In our design mock-up, we only considered one activity update per user; supporting multiple updates even on one day for each user is desirable. A solution is to display a number next to the activity update icon indicating the amount of updates. A more considerable issue is how to visualize activity updates that are threaded. For example, one could imagine having a response update (in addition to the three types we mentioned earlier) that acknowledges other activity updates later in time. Such threading can be shown by representing related activity updates with the same color on the timeline or by highlighting all related activity updates if one of them is selected.

\section{CONCLUSION AND FUTURE WORK}

When we think of creativity as a vital and continual characteristic of intellectual work activity, instead of as unpredictable and singular lightning bolts, we are led to consider support for creativity far more broadly. For example, when collaboratively writing a research paper, creativity support tools such as a shared white-boarding application may support the brainstorming phase of a group's creative process. But this is just a piece of what it could mean to support creative work. When creativity is taken as a long-term, complex activity, support for awareness is also required for group members to monitor the development of ideas, track how these ideas got narrowed down to a few alternatives, and to stay cognizant of how the alternatives are being implemented and integrated by other group members.

In this paper, we argued that it is important to investigate how awareness can support creativity. Our study shows that different types of breakdowns in creativity do occur in distributed collaboration and can be supported by designing appropriate activity awareness mechanisms. We will investigate our design strategies as hypotheses in future studies.

Moving creativity research to a more solid footing requires developing a better foundation in measurement. This has been acknowledged in the recent NSF (National Science Foundation) report on creativity support tools [36]. Our study demonstrated the application of five characteristics (social influence, information sharing, shared understanding, divergent thinking, and convergent thinking) to measure and analyze the process of creativity as a long-term, collaborative activity. We encourage others to further develop and refine our framework of metrics in accordance with their study context.

In our approach to characterize and understand creativity as a long-term activity, product-oriented metrics do not provide as deep and rich of an interpretation as process-oriented metrics. We used our integrated coding scheme to articulate thick descriptions 
of the breakdowns in distributed collaboration by capturing the developmental and evolving nature of the creative process. This could not have been achieved by solely relying on, for example, the group creativity score as a product-oriented measure.

As our immediate work, we are designing subsequent experiments that would involve more groups in order to make statistically significant interpretations. We also plan to take demographic factors and background of participants into account.

\section{ACKNOWLEDGMENTS}

We thank Brian Bailey for his comments on an initial draft of this paper. The first author acknowledges: (a) Phil Ayoub for discussing research issues pertaining to the coding scheme, and (b) his committee members (Lee Giles, Chris Hoadley, Mary Beth Rosson, James Farr, and Rosalie Ocker) for directing the research. This work is partially supported by NSF grant CRI-0454052.

\section{REFERENCES}

[1] Amabile, T.M. Creativity in context: Update to the social psychology of creativity. Westview Press, 1996.

[2] Arias, E.G., Eden, H., Fischer, G., Gorman, A., and Scharff, E. Transcending the Individual Human Mind-Creating Shared Understanding through Collaborative Design. $A C M$ Transactions on CHI, 7, 1 (2000), 84-113.

[3] Arrow, H., McGrath, J.E., and Berdahl, J.L. Small groups as complex systems: Formation, coordination, development, and adaptation. Sage Publications, Thousand Oaks, California, 2000.

[4] Burleson, W. Developing creativity, motivation, and selfactualization with learning systems. Int'l. Journal of HumanComputer Studies, 63 (2005), 436-451.

[5] Carroll, J.M., Neale, D.C., Isenhour, P.L., Rosson, M.B., and McCrickard, D.S. Notification and awareness: synchronizing task-oriented collaborative activity. Int'l. Journal of HumanComputer Studies, 58 (2003), 605-632.

[6] Carroll, J.M., Rosson, M.B., Convertino, G., and Ganoe, C.H. Awareness and teamwork in computer-supported collaboration. Interacting w/ Computers, 18, 1 (2006), 21-46.

[7] Csikszentmihalyi, M. Creativity: Flow and the psychology of discovery and invention. HarperCollins, New York, 1996.

[8] Dourish, P. and Bellotti, V. Awareness and coordination in shared workspaces. In Proceedings of CSCW (Toronto Canada, Oct-Nov 1992), ACM Press, New York, 107-113.

[9] Farooq, U., Carroll, J.M., and Ganoe, C.H. Supporting Creativity in Distributed Scientific Communities. In Proceedings of GROUP (Sanibel Island FL, November 2005), ACM Press, New York, 217-226.

[10] Fischer, G. Distances and diversity: sources for social creativity. In Proc. of Creativity and Cognition (London, April 12-15, 2005), ACM Press, New York, 128-136.

[11] Fitzpatrick, G., Marshall, P., and Phillips, A. CVS Integration with Notification and Chat: Lightweight Software Team Collaboration. In Proc. of CSCW (Banff, Canada, November 4-8, 2006), ACM Press, New York, 49-58.

[12] Foster, G. and Stefik, M. Cognoter: theory and practice of a colab-orative tool. In Proceedings of CSCW (Austin, TX, Dec 3-5, 1986), ACM Press, New York, 7-15.

[13] Ganoe, C.H., Somervell, J.P., Neale, D.C., Isenhour, P.L., Carroll, J.M., Rosson, M.B. and McCrickard, D.S. Classroom BRIDGE: using collaborative public and desktop timelines to support activity awareness. In Proceedings of
UIST (Vancouver Canada, Nov 2-5, 2003), ACM Press, New York, 21-30.

[14] Giaccardi, E. Principles of Metadesign: Processes and Levels of Co-Creation in the New Design Space. Ph.D. Thesis, School of Computing, Plymouth, UK, 2004.

[15] Gough, H. A creative personality scale for the adjective check list. Journal of Personality Social Psychology, 37, 8 (1979), 1398-1405.

[16] Hackman, J.R. (Ed.). Groups that work (and those that don't). Jossey-Bass, San Francisco, 1990.

[17] Janis, I.L. Groupthink: Psychological studies of policy decisions and fiascoes (2nd ed.). Houghton Mifflin, Boston, 1982.

[18] Levine, J.M. and Moreland, R.L. Collaboration: The Social Context of Theory Development. Personality and Social Psychology Review, 8, 2 (2004), 164-172.

[19] Martin, F. Toy Projects Considered Harmful. Communications of the ACM, 49, 7 (2006), 113-116.

[20] Mayer, R.E. Fifty Years of Creativity Research. In R.J. Sternberg (Ed.), Handbook of creativity (pp. 449-460). Cambridge University Press, New York, 1999.

[21] Milliken, F.J. Bartel, C.A., and Kurtzberg, T.R. Diversity and Creativity in Work Groups: A Dynamic Perspective on the Affective and Cognitive Processes that link Diversity and Performance. In P.B. Paulus and B.A. Nijstad (Eds.), Group Creativity: Innovation Through Collaboration (pp. 32-62). Oxford Press, New York, 2003.

[22] Moscovici, S. Social influence I: Conformity and social control. In C. Nemeth (Ed.), Social Psychology: Classic and Contemporary Integrations. Rank McNally, Chicago, 1974.

[23] Nakakoji, K., Yamamoto, Y., and Ohira, M. A framework that supports collective creativity in design using visual images. In Proceedings of Creativity and Cognition (Loughborough, UK, Oct 11-13, 1999), ACM Press, New York, 166-173.

[24] Nemeth, C. and Nemeth-Brown, B. Better than Individuals? The Potential Benefits of Dissent and Diversity. In P.B. Paulus \& B.A. Nijstad (Eds.), Group Creativity: Innovation Through Collaboration (pp. 63-84). Oxford University Press, New York, 2003.

[25] Nickerson, R.S. Enhancing Creativity. In R.J. Sternberg (Ed.), Handbook of creativity (pp. 392-430). Cambridge University Press, New York, 1999.

[26] Ocker, R.J. Influences on creativity in asynchronous virtual teams: A qualitative analysis of experimental teams. IEEE Transactions on Professional Communication, 48, 1 (March 2005), 22-39.

[27] Paulus, P.B. and Nijstad, B.A. (Eds.). Group Creativity: Innovation Through Collaboration. Oxford University Press, New York, 2003.

[28] Rattenbury, T. and Canny, J. CAAD: An automatic task support system. In Proceedings of CHI (San Jose, CA, Apr 28-May 3, 2007), ACM Press, New York, 687-696.

[29] Schmidt, K. The problem with "awareness": Introductory remarks on "awareness in CSCW". Computer Supported Cooperative Work, 11, 3-4 (2002), 285-298.

[30] Stasser, G. and Birchmeier, Z. Group Creativity and Collective Choice. In P.B. Paulus \& B.A. Nijstad (Eds.), Group Creativity: Innovation Through Collaboration (pp. 85-109). Oxford University Press, New York, 2003.

[31] West, M.A. Reflexivity and work group effectiveness: A conceptual integration. In M.A. West (Ed.), Handbook of work group psychology (pp. 555-579). Wiley, Chichester, UK, 1996. 
[32] West, M.A. Reflexivity, revolution, and innovation in work teams. In M.M. Beyerlein, D.A. Johnson, and S.T. Beyerlein (Eds.), Advances in interdisciplinary studies of work teams: Product development teams (pp. 1-29). JAI Press, Stamford, CT, 2000.

[33] West, M.A. Innovation Implementation in Work Teams. In P.B. Paulus and B.A. Nijstad (Eds.), Group Creativity: Innovation Through Collaboration (pp. 245-276). Oxford University Press, New York, 2003.

[34] Westfall, R. Hello, World Considered Harmful. Communications of the ACM, 44, 10 (2001), 129-130.
[35] Winograd, T. and Flores, F. Understanding Computers and Cognition: A New Foundation for Design. Ablex Norwood, New Jersey, 1986.

[36] Workshop on Creativity Support Tools. Available at http://www.cs.umd.edu/hcil/CST/ (last accessed on May 27, 2007). Sponsored by National Science Foundation (Washington DC, June 13-14, 2005).

[37] Yin, R.K. Case study research: design and methods. Sage Publications, Thousand Oaks, California, 2003.

\section{APPENDIX}

Table 3. Coding scheme. First column: Macro- and micro-level codes. Second column: Coded examples from data.

\begin{tabular}{|c|c|}
\hline Codes & Example \\
\hline \multicolumn{2}{|l|}{ Social influences } \\
\hline Groupthink & Jay: We should stick with programming that means coding; Marie: Ok; Hasan: Ok. \\
\hline Normalization & Judy: Maybe we can do something with the animation idea. \\
\hline $\begin{array}{l}\text { Majority } \\
\text { influence }\end{array}$ & $\begin{array}{l}\text { Ahmed: I think the debate is a good idea; Judy: It's not the assignment \{debate idea\}; Chris: } \\
\text { Thanks Judy for elaborating the \{animation\} ideas. }\end{array}$ \\
\hline Polarization & None. \\
\hline $\begin{array}{l}\text { Minority } \\
\text { dissent }\end{array}$ & $\begin{array}{l}\text { Marie: Programming is like cooking, its difficult to talk in the abstract; Jay: Yes, I agree; } \\
\text { Hasan: That's not true...We are trying to teach the concept of a language. }\end{array}$ \\
\hline \multicolumn{2}{|l|}{ Information sharing } \\
\hline $\begin{array}{l}\text { Common information } \\
\text { pooling }\end{array}$ & $\begin{array}{l}\text { Marie: In the Hello World paper, he is obviously talking about teaching OO to students with } \\
\text { procedural language. }\end{array}$ \\
\hline $\begin{array}{l}\text { Unique information } \\
\text { pooling }\end{array}$ & $\begin{array}{l}\text { Sam: I was also thinking maybe we can propose to start not with programming techniques but } \\
\text { something more data-driven, like ajax or web services. }\end{array}$ \\
\hline \multicolumn{2}{|l|}{ Shared understanding } \\
\hline Reflection & Ahmed: I think the assignment is sufficiently amorphous. \\
\hline Planning & Sam: We can make an outline of this and then everyone can contribute to any section. \\
\hline Action/adaptation & Wendy: I can do "Introduction" and "Why start teaching object-oriented language". \\
\hline \multicolumn{2}{|l|}{ Divergent thinking } \\
\hline Generation of multiple perspectives & Jay: We should identify some problems faced by the students. \\
\hline Reflection of multiple perspectives & Marie: Do you have any ideas about what problem we can address? \\
\hline Unique information pooling & Sam: You can't appreciate what's good about OO before some procedural programming. \\
\hline \multicolumn{2}{|l|}{ Convergent thinking } \\
\hline $\begin{array}{l}\text { Critical evaluation of } \\
\text { perspectives }\end{array}$ & $\begin{array}{l}\text { Jay: I don't think algorithm \{the idea of teaching programming using algorithms\} is } \\
\text { appropriate, because in CS, there is another course on algorithms. }\end{array}$ \\
\hline Perspective implementation & Sam: I liked your diagram and I followed up on it in the brainstorming space. \\
\hline
\end{tabular}

